\title{
The ErbB3 receptor tyrosine kinase negatively regulates Paneth cells by PI3K-dependent suppression of Atoh1
}

\author{
Dana Almohazey ${ }^{1,2,3}$, Yuan-Hung Lo ${ }^{4}$, Claire V Vossler ${ }^{1}$, Alan J Simmons ${ }^{5}$, Jonathan J Hsieh ${ }^{1}$, Edie B Bucar ${ }^{1}$, Michael A Schumacher ${ }^{1}$,
} Kathryn E Hamilton ${ }^{6}$, Ken S Lau ${ }^{5}$, Noah F Shroyer ${ }^{4}$ and Mark R Frey ${ }^{\star, 1,7,8}$

Paneth cells (PCs), a secretory population located at the base of the intestinal crypt, support the intestinal stem cells (ISC) with growth factors and participate in innate immunity by releasing antimicrobial peptides, including lysozyme and defensins. PC dysfunction is associated with disorders such as Crohn's disease and necrotizing enterocolitis, but the specific pathways regulating PC development and function are not fully understood. Here we tested the role of the neuregulin receptor ErbB3 in control of PC differentiation and the ISC niche. Intestinal epithelial ErbB3 knockout caused precocious appearance of PCs as early as postnatal day 7, and substantially increased the number of mature PCs in adult mouse ileum. ErbB3 loss had no effect on other secretory lineages, but increased expression of the ISC marker Lgr5. ErbB3-null intestines had elevated levels of the Atoh1 transcription factor, which is required for secretory fate determination, while Atoh $1^{+}$cells had reduced ErbB3, suggesting reciprocal negative regulation. ErbB3-null intestinal progenitor cells showed reduced activation of the PI3K-Akt and ERK MAPK pathways. Inhibiting these pathways in HT29 cells increased levels of ATOH1 and the PC marker LYZ. Conversely, ErbB3 activation suppressed $L Y Z$ and $A T O H 1$ in a PI3K-dependent manner. Expansion of the PC compartment in ErbB3-null intestines was accompanied with elevated ER stress and inflammation markers, raising the possibility that negative regulation of PCs by ErbB3 is necessary to maintain homeostasis. Taken together, our data suggest that ErbB3 restricts PC numbers through PI3K-mediated suppression of Atoh1 levels leading to inhibition of PC differentiation, with important implications for regulation of the ISC niche. Cell Death and Differentiation (2017) 24, 855-865; doi:10.1038/cdd.2017.27; published online 17 March 2017

Paneth cells (PCs) are heavily granulated epithelial cells located at the base of the intestinal crypt, intercalated between crypt base columnar $\left(\right.$ Lgr $\left.^{+}\right)$stem cells. ${ }^{1,2}$ They are a major source of antimicrobial peptides, including lysozyme (encoded by $L y z 1$ in mice) and $a$-defensins. ${ }^{3-5}$ In addition, recent studies on the intestinal stem cell (ISC) niche demonstrated that PCs secrete growth factors (including Wnt ligands and epidermal growth factor (EGF)) that support Lgr5 ${ }^{+}$cells. ${ }^{6}$ Thus, PCs both provide ISCs with growth factors and afford them protection from enteric bacteria.

Alterations in PC number and function have been associated with inflammatory disorders such as Crohn's disease ${ }^{7-9}$ and necrotizing enterocolitis. ${ }^{10}$ Mouse models with PC dysfunction ${ }^{11}$ demonstrate a critical role for these cells in maintaining intestinal homeostasis and preventing colitis. Thus, PCs may provide a key to new avenues of treatment for intestinal inflammation. Although several transcription factors involved in their differentiation have been outlined and a role for morphogens such as Wnt and Notch has been demonstrated in their maintenance, ${ }^{12-14}$ little is known about other growth factor-mediated signaling pathways that regulate PC development or function.
The ErbB3 neuregulin (NRG) receptor-a member of the EGF receptor (EGFR)-related ErbB tyrosine kinase family-is expressed in most epithelial tissues, but its physiological functions specific to each tissue are not well defined. Along with ErbB4, ErbB3 is one of the two receptors for neuregulins in mammalian cells. With a more restricted ligand affinity (preferred recognition for NRG1 and 2) than ErbB4 (which recognizes NRG1-4), ${ }^{15}$ six YXXM phosphatidylinositol 3-kinase (PI3K) docking sites, ${ }^{16}$ and low but physiologically relevant kinase activity, ${ }^{17,18}$ ErbB3 is biochemically unique, and is likely to have roles in cell signaling different than those of other ErbBs.

Although ErbB3 is robustly expressed in the intestinal epithelium, ${ }^{19}$ its function in this tissue is not well understood. In the colon, ErbB3 not only promotes recovery from chemically induced colitis, ${ }^{20}$ but also supports the survival of transformed cells ${ }^{19}$ through mechanisms that remain undefined. Even less is known about ErbB3's role in the small intestine. As the other neuregulin receptor, ErbB4, is protective for $\mathrm{PCs},{ }^{21}$ we tested whether ErbB3 also regulates these cells. We report that, in contrast to ErbB4, ErbB3 signaling restricts the number of

\footnotetext{
${ }^{1}$ The Saban Research Institute, Children's Hospital Los Angeles, Los Angeles, CA, USA; ${ }^{2}$ University of Southern California Herman Ostrow School of Dentistry, Los Angeles, CA, USA; ${ }^{3}$ Institute for Research and Medical Consultations, University of Dammam, Dammam, Saudi Arabia; ${ }^{4}$ Section of Gastroenterology and Hepatology, Department of Medicine, Baylor College of Medicine, Houston, TX, USA; ${ }^{5}$ Epithelial Biology Center, Department of Cell and Developmental Biology, Vanderbilt University Medical Center, Nashville, TN, USA; ${ }^{6}$ Division of Gastroenterology, Department of Medicine, University of Pennsylvania Perelman School of Medicine, Philadelphia, PA, USA; ${ }^{7}$ Department of Pediatrics, University of Southern California Keck School of Medicine, Los Angeles, CA, USA and ${ }^{8}$ Department of Biochemistry and Molecular Biology, University of Southern California Keck School of Medicine, Los Angeles, CA, USA

*Corresponding author: Dr MR Frey, The Saban Research Institute, Children's Hospital Los Angeles, 4650 Sunset Boulevard, MS\#137, Los Angeles, CA 90027, USA. Tel: 323 361-7204; E-mail: mfrey@usc.edu

Received 15.8.16; revised 27.1.17; accepted 14.2.17; Edited by P Bouillet; published online 17.3.2017
} 
a

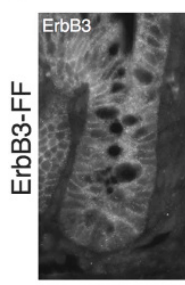

b
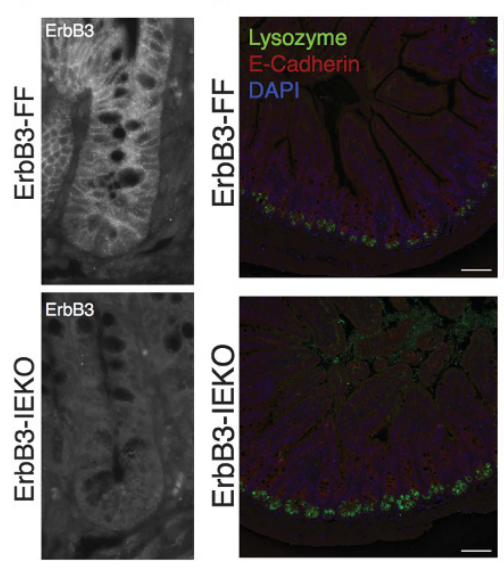

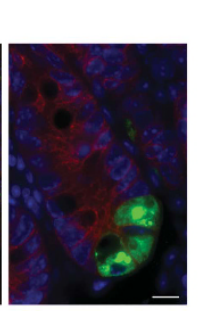

c
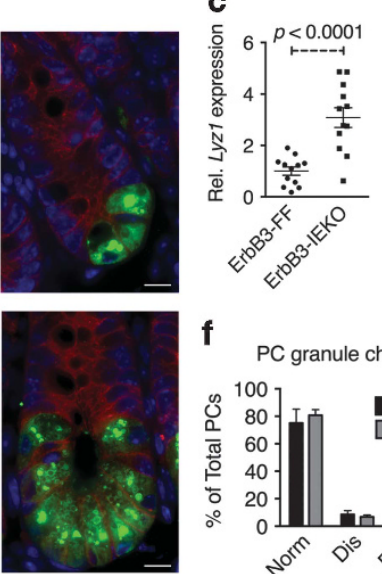

d

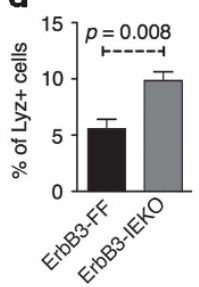

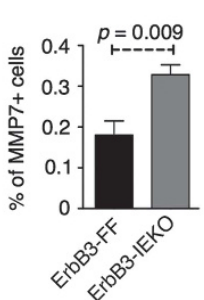

e

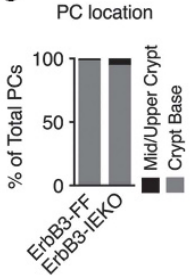

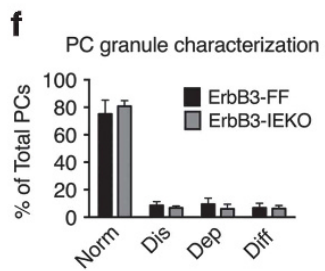
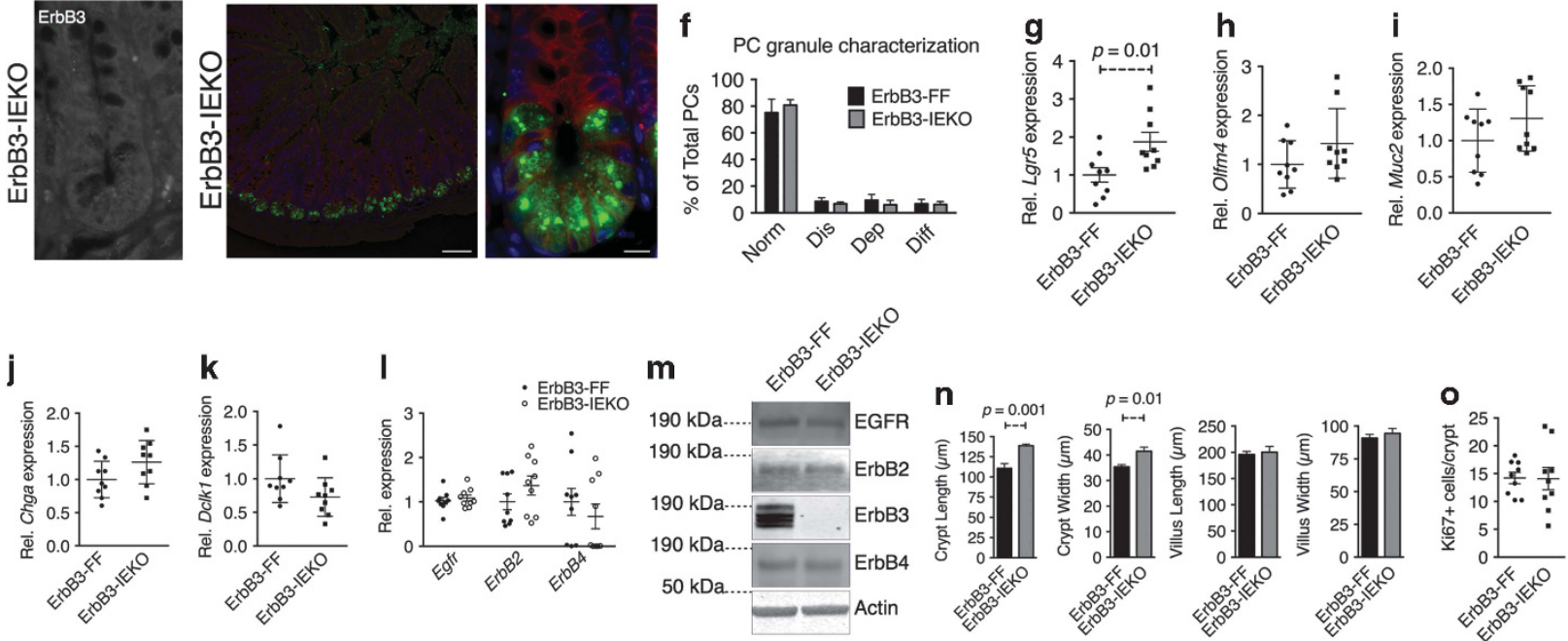

Figure 1 ErbB3-null intestinal crypts have more Paneth cells versus wild type. (a) Immunofluorescence analysis for ErbB3 on paraffin-embedded tissue sections from ErbB3-FF and ErbB3-IEKO ileal crypts showing normal expression throughout the epithelium and confirming knockout. (b) Immunofluorescence analysis for lysozyme (green), E-cadherin (red) and DAPI (blue) on paraffin-embedded tissue sections from ErbB3-FF and ErbB3-IEKO ileums. Scale bars, $75 \mu \mathrm{m}$ ( $\times 10$ images) and $10 \mu \mathrm{m}$ ( $\times 40 \mathrm{images}$ ). (c) qPCR analysis (Cdh1 as reference) of ileal epithelial scrapings for $L y z 1$ ( $n=9$ mice/genotype). (d) CyTOF analysis for PCs (lysozyme ${ }^{+}$or MMP7 $7^{+}$) as a percentage of epithelial cells $(n=5$ mice/genotype). (e and f) PC location (below or above +4 cell position) and PC granule characterization (Norm-normal, Dis-disordered, Dep-depleted and Diff-diffuse) in $\geqslant 40 \mathrm{crypts} / \mathrm{mouse}$ ( $n=4$ mice/genotype). (g-l) qPCR analysis for indicated gene products ( $n=9$ mice/genotype). ( $m$ ) western blot analysis for ErbB protein expression (representative of three mice/genotype examined). (n) Crypt and villus length and width ( $n \geqslant 4$ mice/genotype). (o) Ki67-positive cells per crypt ( $n=9$ mice/genotype). Error bars, \pm S.E.M

mature PCs in the small intestine. This response requires PI3K signaling, which in turn suppresses expression of Atoh1, a transcription factor required for secretory differentiation. These data suggest that ErbB3 has an unexpected role in intestinal cell fate determination. Signaling through the two neuregulin receptors may provide balanced, opposing effects on PCs, ultimately fine-tuning this secretory population and the intestinal stem cell niche.

\section{Results}

ErbB3-null intestinal crypts have an expanded PC compartment. To test the role of ErbB3 in $\mathrm{PC}$ regulation, we deleted it in the intestinal epithelium (ErbB3-IEKO) by crossing ErbB3 $3^{\text {flox/flox }}$ and Villin-Cre mice ${ }^{19}$ (Figure 1a). Histological and immunofluorescence analyses showed an increase in lysozyme ${ }^{+}$PC numbers in ErbB3-IEKO mice compared with control littermates (Figure 1b). Similarly, quantitative PCR (qPCR) on mucosal lysates revealed a doubling in $L y z 1$ expression (Figure 1c), and Cytometry by Time of Flight (CyTOF) analysis on dissociated epithelium showed an increased proportion of cells expressing the PC markers lysozyme and matrix metalloproteinase-7 (MMP7; Figure 1d). The additional PCs were located, as normal, at the crypt base with normal granule morphology (Figures 1e and f), suggesting normal function. ${ }^{9,22}$ Consistent with the demonstrated role of PCs in supporting ISCs through Wnt production, there was an increase in the Wnt-regulated ISC marker Lgr5, but not the Notch-regulated Olfm4 (Figures $1 \mathrm{~g}$ and h). ErbB3 deletion did not alter the expression of other secretory cell markers such as Muc2 (goblet cells), Chga (enteroendocrine cells) or Dclk1 (tuft cells; Figures 1i-k), suggesting a specific effect on PCs rather than overall expansion of the secretory lineages. We did not detect altered expression of other ErbB family members in ErbB3IEKO mice, ruling out a role for compensatory changes in these receptors (Figures $1 \mathrm{l}$ and $\mathrm{m}$ ). Morphometric analysis supported the idea that alterations in these mice are restricted to the crypt, showing a significant increase in crypt length and width in the ErbB3-IEKO animals versus littermate controls, but no change on the villi (Figure 1n). Moreover, the numbers of proliferative cells in the crypts were not different (Figure 10), suggesting that morphological changes were not driven by cell division and thus might be due to differentiation into the larger-sized Paneth cells.

Paneth cells develop precociously in ErbB3-IEKO mice. The selective increase of PCs in ErbB3-IEKO mice could represent accelerated development of this lineage. Thus, we examined intestines at postnatal day $(P) 7$, when the mouse 
a

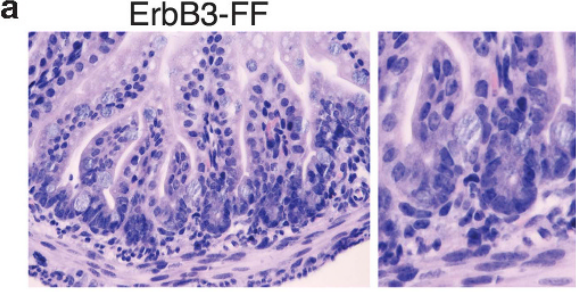

b
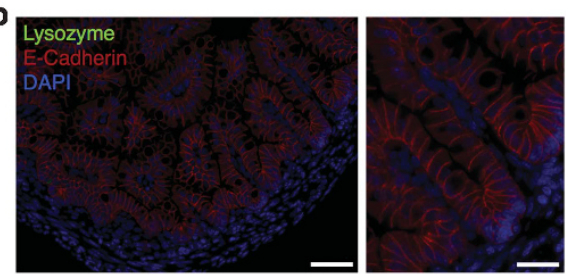

C

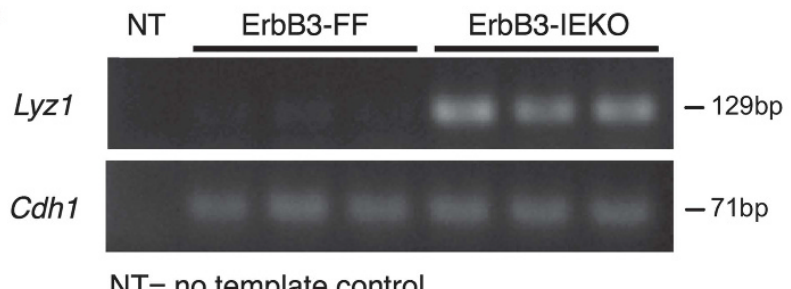

$\mathrm{NT}=$ no template control
ErbB3-IEKO
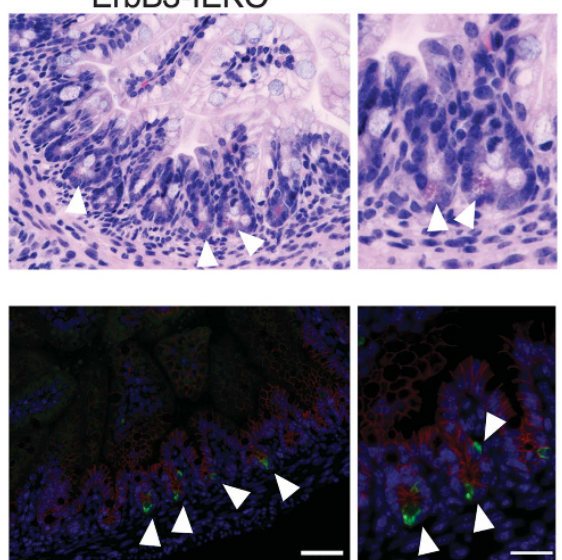

Figure 2 ErbB3-null intestines express Paneth cell markers by postnatal day 7. (a) H\&E on paraffin-embedded tissue sections from ErbB3-FF and ErbB3-IEKO ileums collected at postnatal day 7. (b) Immunofluorescence analysis for lysozyme (green), E-cadherin (red) and DAPI (blue). Scale bars, $50 \mu \mathrm{m}$ ( $\times 20 \mathrm{images})$ and $25 \mu \mathrm{m}$ ( $\times 40 \mathrm{images).}$ Arrowheads, example granulated/lysozyme ${ }^{+}$cells. (c) RT-PCR analysis (Cdh1 as reference) of ileal whole-tissue homogenates for $L y z 1$ (representative results of $n=6$ mice/ genotype)

ileum is normally devoid of mature lysozyme ${ }^{+} \mathrm{PCs}^{4,23} \mathrm{We}$ observed granulated cells near the intestinal crypt base in P7 ErbB3-IEKO mice, but not littermate controls (Figure 2a). The presence of lysozyme ${ }^{+}$cells in the knockouts was confirmed by immunofluorescence (Figure 2b) and reversetranscriptase PCR (RT-PCR; Figure 2c). Although lysozyme was not as highly expressed in ErbB3-IEKO P7 pups as in adults, it was clearly present and at a similar level as in $\mathrm{P} 13$ WT mice (not shown). Thus, ErbB3 deletion allows premature appearance of differentiated PCs, with elevated numbers maintained into adulthood.

ErbB3-null intestinal crypts have more MMP7/MUC2 ${ }^{+}$ intermediate cells versus wild type. PCs and goblet cells share a common secretory precursor, which can be identified by simultaneous expression of MMP7 and MUC2. ${ }^{13,24}$ Immunofluorescence analysis showed an increase in double-positive cells in ErbB3-IEKO mice (Figures $3 a$ and b). We speculate that most of these additional precursors preferentially differentiate to PCs, as we did not detect any overall alteration in Muc2 expression (Figure 1i). These results suggest that the deletion of ErbB3 selectively drives cell fate commitment towards PC differentiation.

Atoh1 binds to the ErbB3 promoter region and downregulates its expression. We next asked whether ErbB3 has functional interactions with Atoh1, a transcription factor expressed in MMP7/MUC2 $^{+}$intermediate cells that is required for secretory cell fate determination. ${ }^{25,26}$ Chromatin immunoprecipitation (ChIP) analysis showed that Atoh1 binds the ErbB3 promoter region (Figures $4 a$ and b). Furthermore, Atoh $1^{+}$cells had reduced ErbB3 expression (Figure 4c), and transient ATOH1 transfection in mouse small intestinal and colonic cell lines repressed ErbB3 expression (Figure 4d). Conversely, ErbB3-IEKO intestines showed elevated Atoh1 (Figure 4e), suggesting a negative feedback loop between Atoh1 and ErbB3.

NRG1 $\beta$ exposure reduced expression of Paneth and stem cell, but not goblet cell, markers in enteroid cultures. To investigate the effects of activating ErbB3 in a readily tractable model, we treated ileal enteroid cultures ${ }^{6}$ from C57BI/6 mice with NRG1 $\beta(10 \mathrm{ng} / \mathrm{ml})$. Consistent with the hypothesis that ErbB3 restricts PC numbers, NRG1 $\beta$ repressed expression of $L y z 1$ (Figure $5 a$ ), as well as Defa5, which encodes another antimicrobial peptide produced by PCs. In contrast, Muc2 levels were largely unchanged, consistent with the in vivo ErbB3-IEKO results. We also observed a reduction in Lgr5 (Figure $5 \mathrm{~b}$ ), and to a lesser extent in Lrig1 and Bmi1. This could represent the close dependence of the $\mathrm{Lgr5}^{+}$ISCs on PCs. ${ }^{6}$ A $24 \mathrm{~h}$ NRG1 $\beta$ exposure was sufficient to deplete PC and ISC markers (Figure 5c). Immunofluorescence analysis revealed that NRG1 $\beta$ drives a decrease in lysozyme ${ }^{+}$cells, suggesting fewer PCs as opposed to reduced antimicrobial peptide expression per PC (Figure $5 d$ ). There were no changes in proliferation with NRG1 $\beta$ exposure (Figure 5e); consistent with this, enteroid sizes (measured by cross-sectional area) in cultures from ErbB3-IEKO mice and control littermates were not different (not shown). 
a

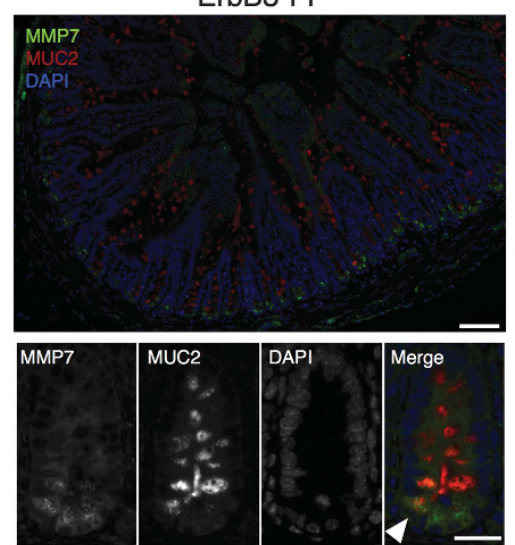

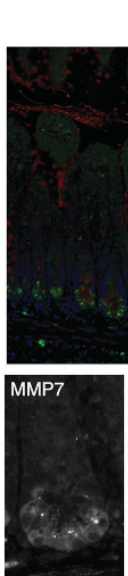

ErbB3-IEKO

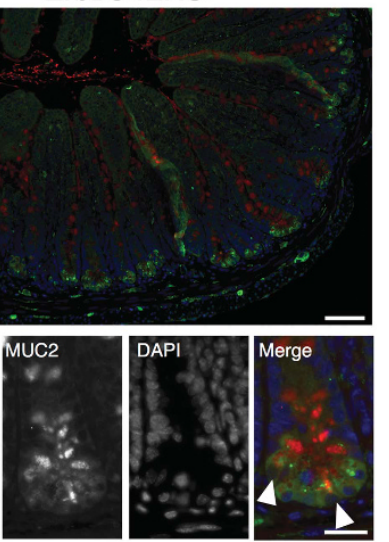

b

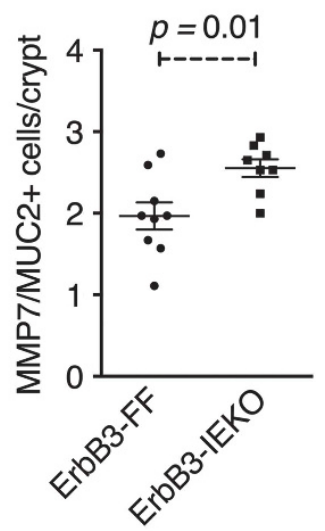

Figure 3 ErbB3-null intestinal crypts have more MMP7/MUC2 ${ }^{+}$intermediate cells versus wild type. (a) Immunofluorescence analysis for MMP7 (green), MUC2 (red) and DAPI (blue) on paraffin-embedded sections from ErbB3-FF and ErbB3-IEKO ileums. Scale bars, $75 \mu \mathrm{m}$ ( $\times 10$ images) and $25 \mu \mathrm{m}$ ( $\times 40$ images). Arrowheads, example double-positive cells. (b) Quantification of MMP7/MUC2 ${ }^{+}$cells/crypt ( $n=9$ mice/genotype). Error bars, \pm S.E.M

a

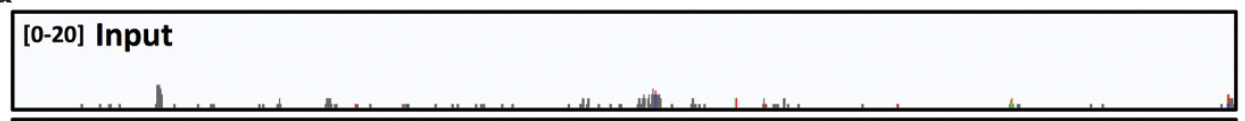

\begin{tabular}{|c|c|}
\hline [0-20] Atoh1 & \\
$\perp$ & $, \|_{1} \quad, \quad$ \\
\hline
\end{tabular}

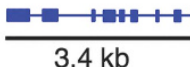

b

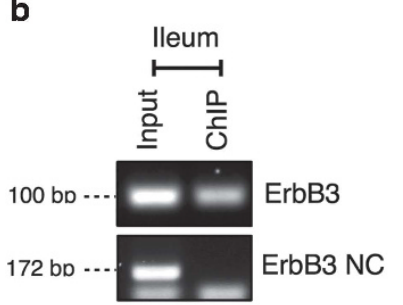

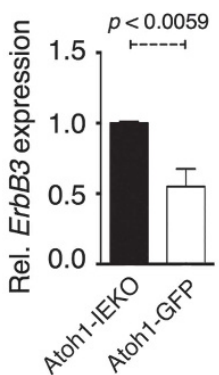

d

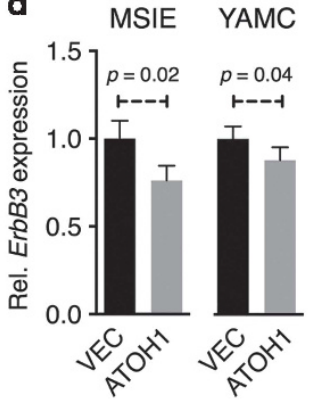

Erbb3

e

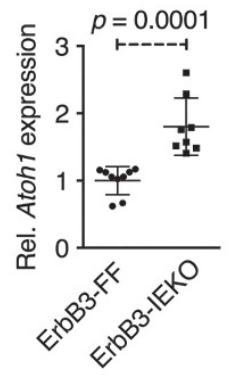

Figure 4 Atoh1 binds to ErbB3 promoter region and downregulates its expression. (a) CHIP-seq performed on sorted Atoh1-GFP+ ${ }^{+}$cells from Atoh1 ${ }^{\text {GFP/GFP }}$ mice. The peak density plots show enrichment of Atoh1 peak (lower box). Erbb3 gene is labeled with exons as thick rectangles (representative of three independent sorts). (b) ErbB3 PCR performed on CHIP product from Atoh $1{ }^{\text {Flag/Flag }}$ mice (representative of three independent experiments). ErbB3 NC is a negative control region $5 \mathrm{~kb}$ upstream of Atoh1 binding region. (c) RNA-seq analysis of Atoh1-IEKO and sorted Atoh1-GFP+ cells for ErbB3. (d) qPCR analysis for ErbB3 (Hprt as reference) of MSIE (mouse small intestine) and YAMC (mouse colon) cells transiently transfected for $48 \mathrm{~h}$ with ATOH1-GFP or vector as indicated ( $n=5$ independent experiments). (e) qPCR analysis (Cdh1 as reference) of ileal epithelial scrapings for Atoh1 in ErbB3-FF and ErbB3-IEKO ( $n=8$ mice/genotype). Error bars, \pm S.E.M

ErbB4 is not required for NRG1 $\beta$-stimulated PC loss. Our previous studies using ErbB4 ligand in intestinal injury models and ErbB4-null enteroids ${ }^{21}$ suggest that ErbB4 is protective for PCs. To compare the results of ErbB4 versus ErbB3 deletion in homeostasis, we examined ErbB4-IEKO ileums. Surprisingly, unchallenged ErbB4-IEKO mice displayed no alterations in PC or ISC markers (Figure 6a). Furthermore, in enteroid cultures from C57BI/6 mice, the ErbB4-specific ligand NRG4 did not provoke any change in Lyz1, Defa5 or Lgr5 (Figure 6b). However, in ErbB4-IEKO enteroids NRG1 $\beta$ was still able to cause a reduction in $L y z 1$ and $L g r 5$ (Figure $6 \mathrm{c}$ ) comparable to that seen in wild-type cultures (Figure 5). Together with our previous studies, these results suggest that ErbB4 primarily has a protective role for PCs after injury or other challenge, but does not substantially impact their homeostatic maintenance. In contrast, ErbB3 restricts the numbers of PCs during normal development and homeostasis.

ErbB3 maintains baseline intestinal epithelial PI3K and MAPK signaling in vivo. ErbB3 stimulates PI3K-Akt and ERK1/2 mitogen-activated protein kinase (MAPK) activation in cultured intestinal cell lines. ${ }^{27}$ MAPK activation also 

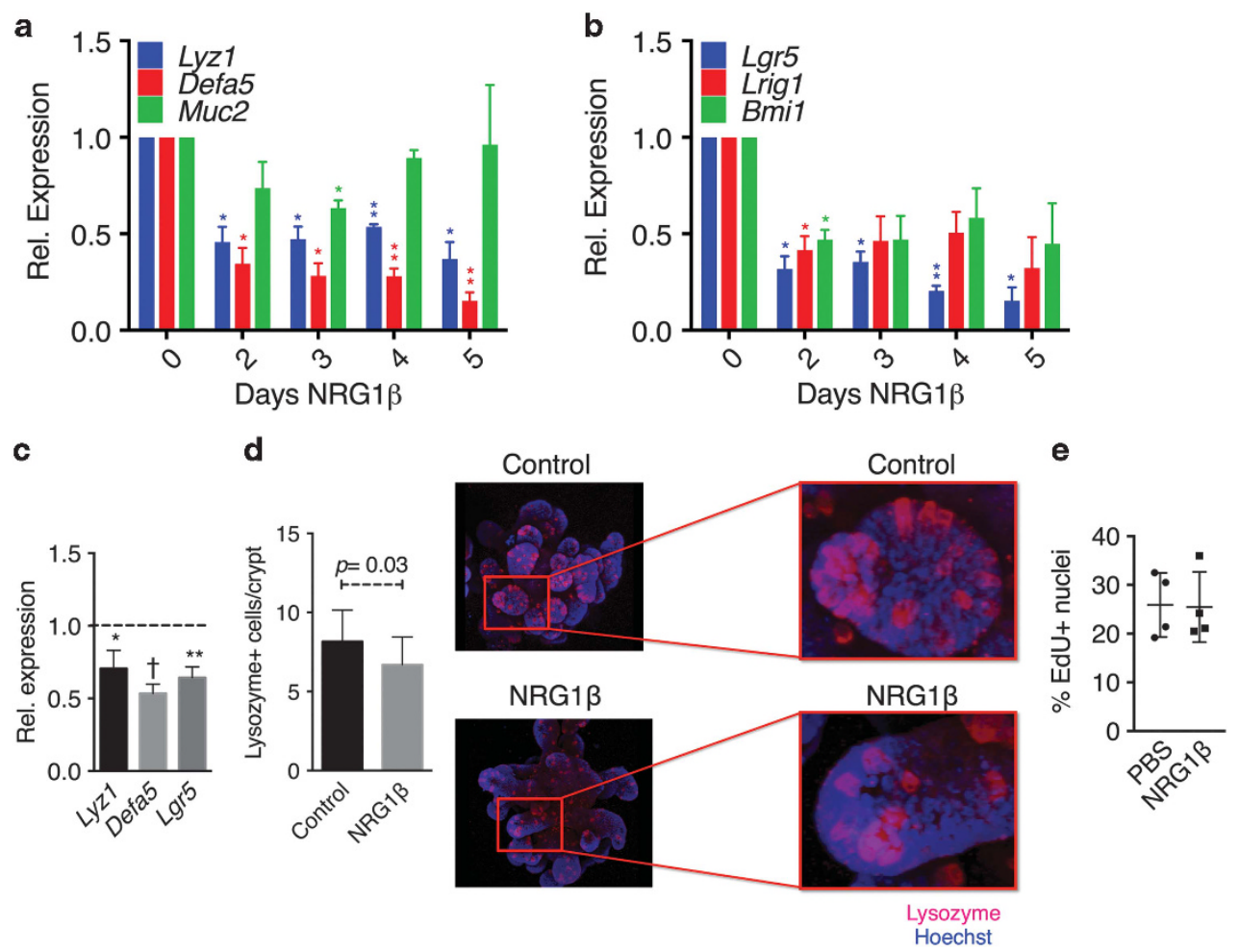

Figure 5 NRG1 $\beta$ exposure reduced expression of Paneth and stem cell, but not goblet cell, markers. (a and $\mathbf{b})$ qPCR analysis (Gapdh as reference) of ileal enteroid cultures treated with NRG1 $\beta(10 \mathrm{ng} / \mathrm{ml}$ ) daily for 5 days for indicated gene products ( $n=3$ independent experiments). (c and d) Enteroids were treated with a single dose of NRG1 $\beta$ for $24 \mathrm{~h}$. (c) qPCR analysis of indicated genes ( $n=3$ independent experiments). Dashed line represents control. (d) Quantification of lysozyme ${ }^{+}$cells in control and NRG1 $\beta$-treated enteroids using in situ immunofluorescence analysis for lysozyme (pink) and Hoechst (blue; $n=3$ independent experiments, 200 crypts/condition). (e) Enteroids were treated with PBS or NRG1 $\beta$ for $48 \mathrm{~h}$, labeled with EdU, fixed and stained ( $n=4$ independent cultures per condition, at least seven enteroids per culture counted). ${ }^{*} P<0.05 ;{ }^{* *} P<0.01$; ${ }^{\dagger} P<0.001$ versus control. Error bars, \pm S.E.M
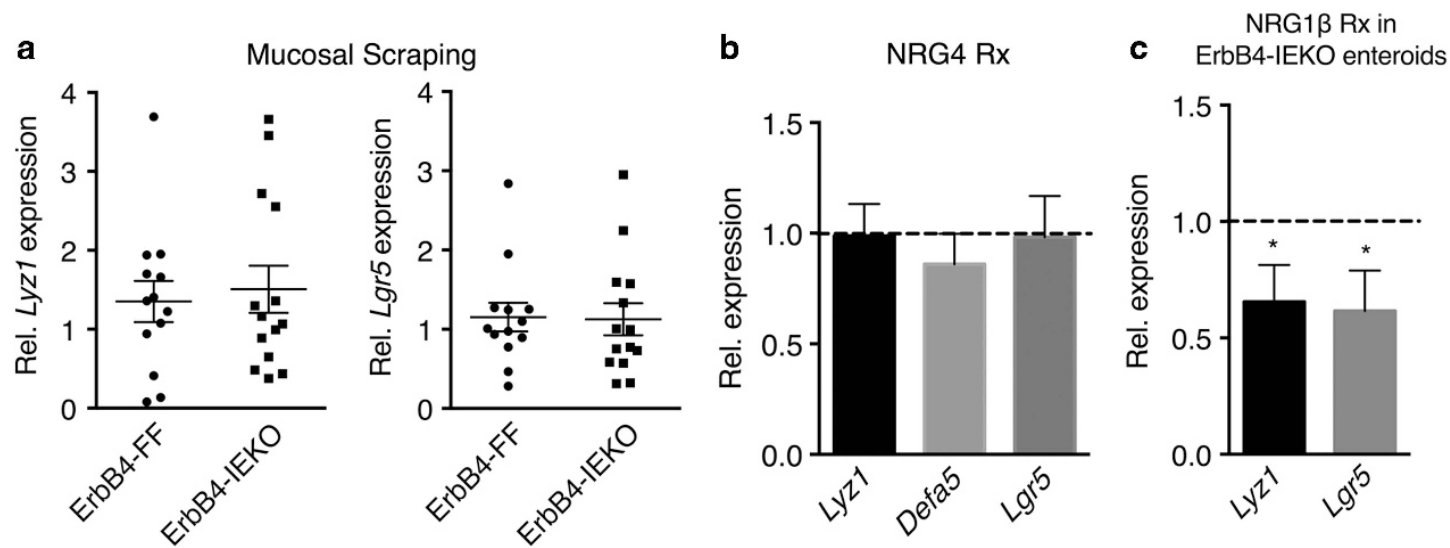

Figure 6 ErbB4 signaling does not affect homeostatic PC or ISC marker levels. (a) qPCR analysis (Cdh1 as reference) of ileal epithelial scrapings from ErbB4-FF and ErbB4-IEKO animals for indicated gene products ( $n=13-14$ mice/genotype). (b) qPCR analysis (Gapdh as reference) of wild-type enteroids treated with ErbB4-specific ligand, NRG4 (100 ng/ml) for $24 \mathrm{~h}(n=4$ independent experiments). (c) qPCR analysis (Gapdh as reference) of ErbB4-IEKO enteroids treated with NRG1 $\beta$ for $24 \mathrm{~h}$. (b and $\mathbf{c}$ ) Dashed line represents control. Error bars, \pm S.E.M. ${ }^{*} P<0.05$

negatively regulates $\mathrm{PC}$ numbers, ${ }^{14}$ which could be related to ErbB3 activity. In contrast, a role for PI3K signaling in PCs has not been investigated. To begin to identify which pathways are responsible for ErbB3 regulation of PCs, we first performed western blot analysis on whole mucosal lysates. In this analysis, only phospho-Akt levels were reduced in ErbB3-IEKO mice (Figures 7a and b). Using the more sensitive CyTOF analysis, which can also define signaling in cellular subsets, we determined that both phospho-Akt and phospho-ERK1/2 were significantly reduced in cytokeratin (CK) $20^{\text {low }} /$ Lysozyme $^{-}$crypt progenitor cells from the ErbB3-IEKO mice as well as, to a lesser extent, in the epithelium overall (Figures 7c and d). In contrast, PCs themselves showed only a nonsignificant trend towards 
a

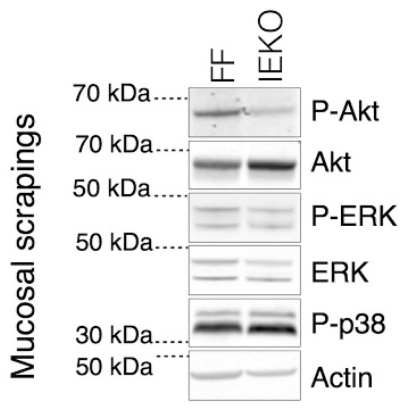

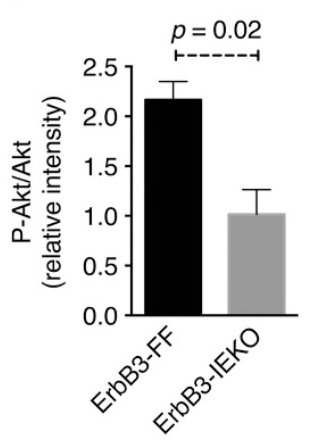

d CK20low/lysozyme- progenitors
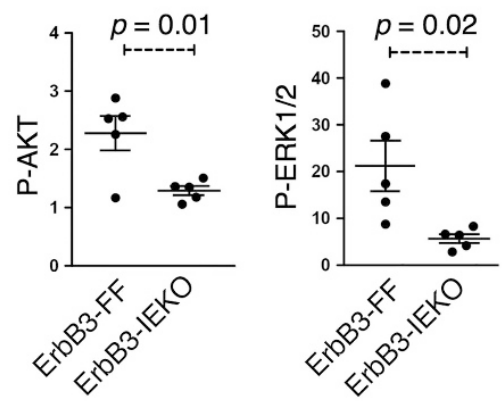

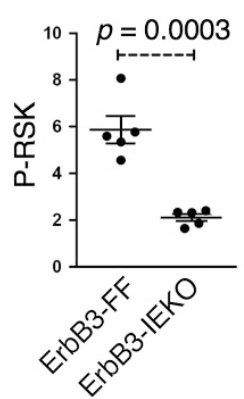

c

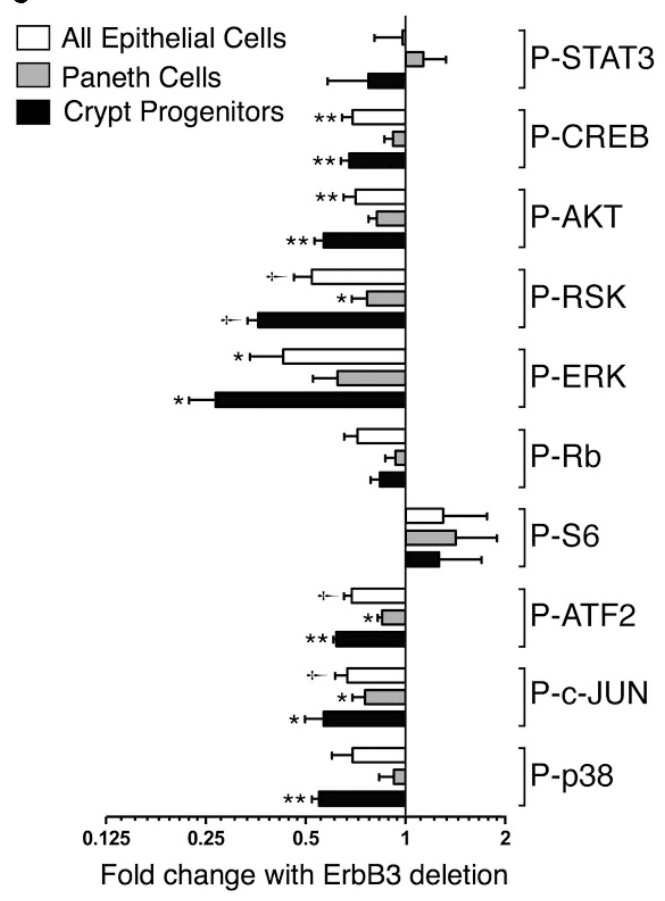

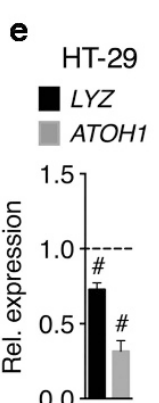

NRG1 $1 \beta++$ f

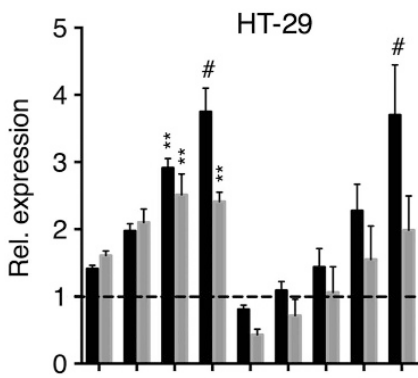

$\operatorname{LY}(\mu \mathrm{M}) 2.551020-2.551020$

NRG1 $\beta---+++++$ g

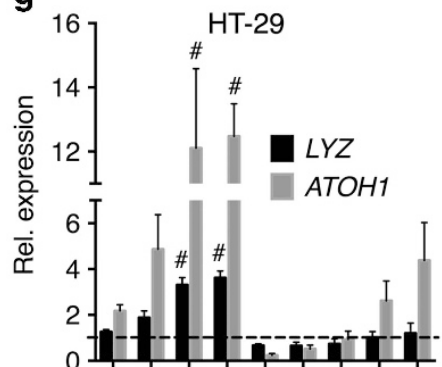

$\mathrm{U}(\mu \mathrm{M}) 1.252 .5510-1.252 .5510$

NRG1 $\beta---+++++$ $\mathbf{h}$

HT-29

i WT enteroids

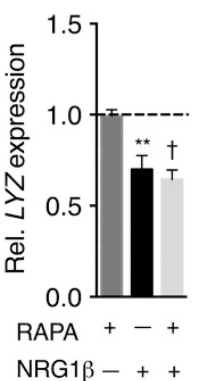

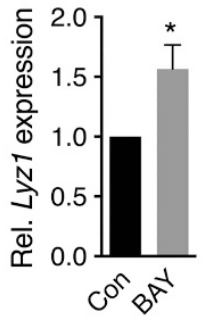

Figure 7 ErbB3 regulates Paneth cells through the PI3K/Akt pathway. (a) Western blot analysis of ileal epithelial scrapings from ErbB3-FF and ErbB3-IEKO mice (representative of three mice/genotype examined). (b) Relative intensity of P-Akt/Akt in a. (c) CyTOF analysis (median fluorescence intensity) of indicated proteins in all epithelial cells (white bars), PCs (lysozyme ${ }^{+}$, gray bars) and crypt progenitors (CK20 low/lysozyme ${ }^{-}$, black bars; $n=5$ mice/genotype). (d) CyTOF analysis of P-Akt (S473), P-ERK1/2 (T202/Y204) and P-RSK (T359/S363) in crypt progenitors (CK20 low/lysozyme ${ }^{-}$). (e-h) qPCR analysis (HPRT as reference) of HT29 cells for LYZ and ATOH1 after $24 \mathrm{~h}$ treatment with NRG1 $\beta(10 \mathrm{ng} / \mathrm{ml}) \pm$ PI3K inhibitor LY294002 (LY, 2.5, 5, 10 and $20 \mu \mathrm{m})$, MEK1/2 inhibitor U0126 (U, 1.25, 2.5, 5 and $10 \mu \mathrm{m})$ and mTORC1 inhibitor Rapamycin (RAPA, $100 \mathrm{nM}$ ). Inhibitors were added an hour before NRG1 $\beta$ treatment ( $n \geqslant 3$ independent experiments per panel). Dashed line represents control. (i) qPCR analysis (HPRT as reference) of C57BI/6 enteroids for $L y z 1$ after $48 \mathrm{~h}$ treatment with vehicle or PI3K inhibitor BAY 80-6946 (50 nM; $n=3$ independent experiments). Error bars, \pm S.E.M. ${ }^{*} P<0.05$; ${ }^{* *} P<0.01 ;{ }^{\dagger} P<0.001 ;{ }^{\#} P<0.0001$ versus control.

reduced activity of these pathways (Figure 7c). Thus, changes in PC numbers in ErbB3-IEKO mice may be a consequence of altered signaling specifically in the stem cell/progenitor compartment.

ErbB3 regulates Paneth cells through the PI3K-Akt pathway. To define the involvement of PI3K and MAPK in ErbB3 regulation of PCs, we used HT29 human colorectal cancer cells. Unlike in the mouse, Paneth cells can be observed in the human colon, and colonic Paneth cell metaplasia has been reported in inflammation and cancerous conditions. $^{7,28,29}$ HT29 cells express both secretory and absorptive characteristics and have been used to study mechanisms controlling Paneth/goblet cell balance. ${ }^{14,30}$ NRG1 $\beta$ elicited a reduction in baseline $L Y Z$ and $A T O H 1$ expression in these cells (Figures 7e-g). Conversely, PI3K and MAPK inhibitors caused dose-dependent increases in $L Y Z$ and $A T O H 1$ (Figures $7 f$ and $g$ ). These data suggest that baseline activities of PI3K and MAPK are involved in restricting $L Y Z$ and $A T O H 1$ levels. The mTORC1 inhibitor Rapamycin had no effect (Figure $7 \mathrm{~h}$ ), indicating that PI3K involvement is selectively through Akt or possibly mTORC2. Interestingly, PI3K inhibition could induce $L Y Z$ and $A T O H 1$ in the presence of NRG1 $\beta$, while MAPK inhibition could not. Thus, although PI3K and MAPK are both involved in the regulation of $\mathrm{PCs}$, only $\mathrm{PI} K \mathrm{~K}$ signaling is required for ErbB3- 
a

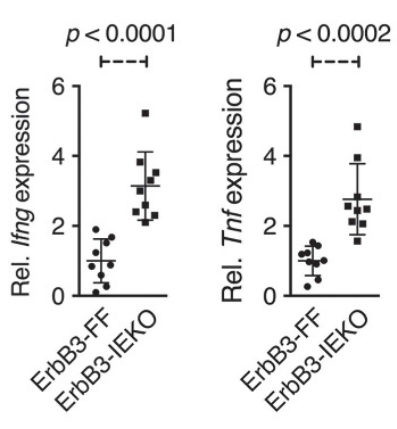

d
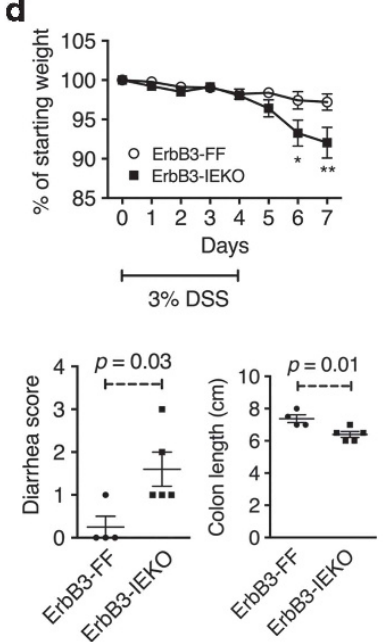
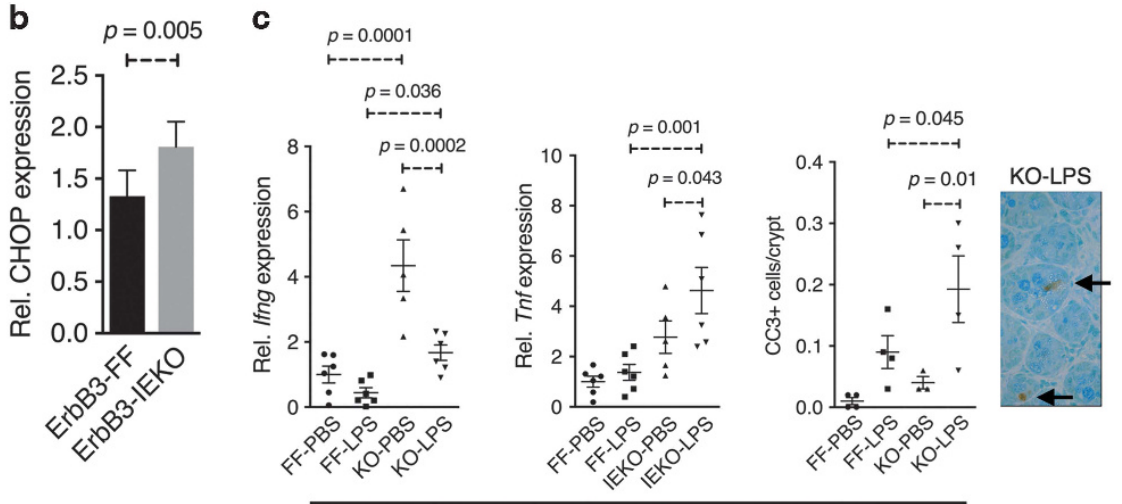

$24 \mathrm{~h}$, ileum

e

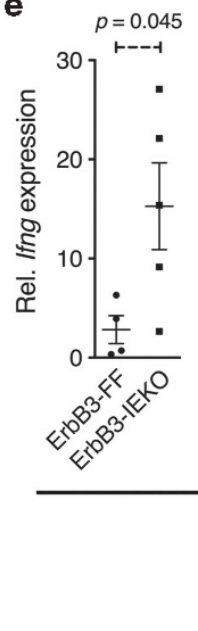

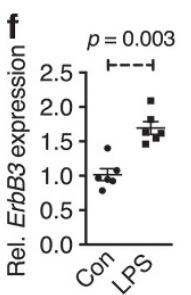
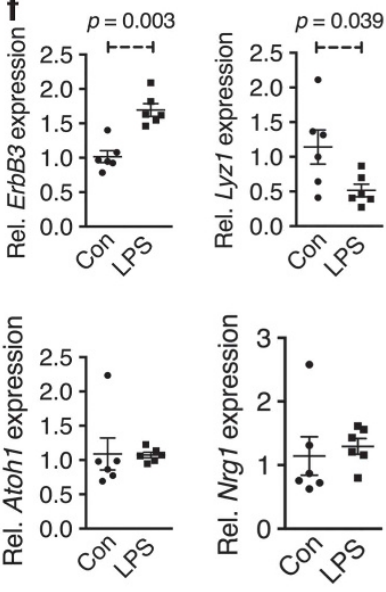

$24 \mathrm{~h}$, ileum

Figure 8 The ErbB3-null ileal epithelium is sensitized to inflammation. (a) qPCR analysis (Cdh1 as reference) of ileal epithelial scrapings from ErbB3-FF and ErbB3-IEKO mice for Ifng and $\operatorname{Tnf}(n=9$ mice/genotype). (b) Western blot analysis of ileal epithelial scrapings for $\mathrm{CHOP}$ was performed and quantified by densitometry ( $n=8$ mice/genotype). (c) Mice were challenged with PBS or $10 \mathrm{mg} / \mathrm{kg}$ LPS by intraperitoneal injection; ileal epithelial scrapings were collected after $24 \mathrm{~h}$ and qPCR analysis (Cdh1 as reference) for Ifng and Tnf was performed ( $n=6$ per condition); paraffin-embedded sections were immunostained for cleaved caspase-3 (CC3) and positive cells in crypts were counted. (d and $\mathbf{e}$ ) Mice were subjected to DSS colitis; (d) weight over time, colon lengths at necropsy and stool consistency were recorded. (e) lleal epithelial scrapings were collected and qPCR analysis (Cdh1 as reference) for Ifng and Tnf was performed ( $n=4-5$ per condition); tissue sections were immunostained for Ki67 and positive cells per crypt were quantified. (f) Wild-type C57B//6 mice were given PBS or LPS injections; ileal epithelial scrapings were collected after $24 \mathrm{~h}$ and qPCR analysis (Cdh1 as reference) was performed for ErbB3, Atoh1, Lyz1 and Nrg1. Error bars, \pm S.E.M. ${ }^{*} P<0.05 ;{ }^{* *} P<0.01$

mediated effects on this lineage. In wild-type enteroids, the PI3K inhibitor BAY 80-6946 induced Lyz1 (Figure 7i), demonstrating the importance of $\mathrm{PI} K$ Kor suppressing lysozyme in a model with fully differentiated PCs.

The ErbB3-null ileal epithelium is sensitized to inflammation. Epithelial ErbB3 knockout has been associated with poor recovery from colonic injury, ${ }^{20}$ and an expanded PC compartment has been associated with ER stress and inflammation. $^{31}$ Therefore, we tested small intestinal inflammatory responses in ErbB3-IEKO mice. At baseline, ErbB3-IEKO intestines had elevated interferon (IFN) $-\gamma$ and tumor necrosis factor (TNF) mRNA (Figure 8a), and increased protein levels of the ER stress marker $\mathrm{CHOP}$ (Figure 8b) versus control littermates. In the acute LPS injection enteritis model, knockouts displayed elevated IFN- $\gamma$ and TNF levels and more apoptotic cells in the ileal crypts (Figure $8 \mathrm{c}$ ). No change in villus apoptosis was noted (not shown). In DSS colitis, ErbB3-IEKO animals had enhanced disease (Figure $8 d$ ), similar to previous reports. ${ }^{20}$ Intriguingly, the knockouts also had elevated ileal IFN- $\gamma$ and TNF responses (Figure 8e), even though there is no frank ileal injury with DSS. Rare apoptotic cells in the lower ileal crypts could be identified after DSS challenge only in the knockouts, never the ErbB3-replete littermates (not shown). We found no differences in proliferation (Figure 8e). As inflammation sometimes drives colonic PC metaplasia, we measured $L y z 1$ in the proximal colons of ErbB3-FF and ErbB3-IEKO mice, \pm DSS colitis. We found weak but detectable expression in all groups, but no differences between control and DSS or between genotypes. This may indicate that the effects of ErbB3 on secretory differentiation are restricted to the small intestine. We also tested the effects of inflammation on ErbB3 in the ileum, finding no change in ErbB3 or Nrg1 in DSS colitis (not shown), consistent with the relative lack of 
effect of DSS on the ileum. In contrast, LPS injection induced ErbB3 expression and reduced $L y z 1$ levels (Figure 8f).

\section{Discussion}

Herein we report that the ErbB3 neuregulin receptor limits PC numbers in the intestinal crypt. ErbB3 deletion resulted in an increase in morphologically normal PCs in adult mice and early appearance of these cells in the developing intestine (Figures 1 and 2). Consistent with the role PCs can have in supplying ISCs with Wnt and growth factors, this was accompanied by elevated Lgr5, but no change in markers for other cell lineages (Figure 1). We did observe an increase in MMP7-MUC2 double-positive intermediate cells in ErbB3IEKO mice (Figure 3), and demonstrated that ErbB3 and the secretory regulator Atoh1 are reciprocally balanced (Figure 4). The ErbB3 ligand NRG1 $\beta$ downregulated PC and ISC markers in culture models (Figures 5,6,7), apparently through altered PI3K-Akt activation (Figure 7). ErbB3-IEKO mice also had elevated inflammation and ER stress markers (Figure 8), suggesting that expansion of the PC compartment beyond normal physiologic numbers is associated with a loss of homeostasis. Taken together, our results position ErbB3 as an important regulator of PC differentiation.

We previously demonstrated that the related receptor ErbB4 protects PCs in injury models and enteroids. ${ }^{21}$ NRG1 $\beta$ (binds both ErbB3 and ErbB4) stimulated Lyz1 loss even in ErbB4null enteroids, while WT enteroids treated with NRG4 (activates ErbB4 but not ErbB3) did not suppress PC or ISC markers (Figure 6). Thus it appears that ErbB3 and ErbB4 have different, even opposing functions with regard to $P C$ maintenance. This is particularly interesting in that the balance of NRG1 $\beta$ versus NRG4 shifts during inflammation, ${ }^{27,33}$ which could lead to an altered PC population. This could, in turn, impact the ISC niche through the growth factors produced by the PCs, as well as predisposing to an altered microbiota through changes in antimicrobial peptide release.

Although our results exclude a requirement for ErbB4 in ErbB3-mediated restriction of PCs, it will be important to determine whether heterodimerization with either EGFR or ErbB2 is necessary. ErbB3 was initially thought to be kinase inactive and therefore dependent on heterodimerization. ${ }^{17,34,35}$ More recent studies established that its kinase activity, while low, is sufficient for physiologically relevant signaling. ErbB3 is competent to bind ATP and autophosphorylate, although much more weakly than EGFR, and can form homodimers. ${ }^{18,36,37}$ Another unique feature of ErbB3 is that it has six YXXM docking sites for the $\mathrm{SH} 2$ domain of the p85 PI3K regulatory subunit. $^{16,38}$ The presence of six YXXM motifs makes ErbB3 a stronger activator of the PI3K-Akt pathway than other ErbBs. Given the impact of PI3K signaling on $L Y Z$ and ATOH1 expression (Figure 7), the difference between ErbB3 homodimers versus heterodimers with EGFR or ErbB2 may be functional in fine-tuning this regulatory mechanism.

To date, little is known about the physiology of ErbB3 in the intestine. ErbB3-IEKO mice had impaired recovery from DSS colitis, ${ }^{20}$ and our results are consistent with this (Figure 8). Although PC loss or dysfunction is often a feature of intestinal inflammation, ${ }^{7-11}$ the baseline increase in an ER stress marker (CHOP) and inflammatory cytokines (TNF, IFN- $\gamma$ ) in the ErbB3-IEKO ileums may indicate that an over-expansion of PCs is also not benign. While ErbB3 is typically thought of as a growth and survival signal (though it is dispensable for epithelial proliferation, Figures 10 and $8 \mathrm{e}$ ) it may be that restricting PC development to prevent a hyper-secretory, ER-stressed phenotype is an important homeostatic function of this receptor. ErbB3-null PCs, despite having a normal appearance, may be more susceptible to injury and inflammation due to baseline ER stress, which has been previously associated with PC expansion or dysfunction. ${ }^{11,31}$ However, as described by Threadgill and colleagues, ErbB3 also provides a strong survival signal for colonocytes. ${ }^{19}$ ErbB3 likely has multiple context-dependent functions in the gut, and direct effects on both enterocyte survival and PC development may be important. Future studies with targeted deletion in PCs and specific progenitor subsets are needed to better understand which cell types are driving which effects of ErbB3 loss.

PCs secrete products (EGF, Notch, Wnt ligands) that support Lgr5 ${ }^{+}$ISCs. $^{6}$ In ErbB3-IEKO mice, an increase in $P C$ numbers, and therefore Wnt, might drive an accumulation of Atoh1 that feeds into a loop resulting in a further increase in the secretory cell lineage. However, we should note that in LPS-treated C57BI/6 mice, we saw increased ErbB3 and decreased $L y z 1$ without alterations in Atoh1 (Figure 8f). This may indicate that during inflammation ErbB3 has an additional mechanism of regulating PCs without affecting Atoh1, or it could be that the complexity of the acute $(24 \mathrm{~h})$ LPS model is masking the response. Conditional Atoh1 knockout results in a loss of all intestinal secretory lineages. ${ }^{26}$ Inversely, Notch inhibition had the opposite outcome as well as a reduction in the ISC markers Olfm4 and Lgr5. ${ }^{13}$ However, in neither of these cases was the effect specific to PCs as it is with ErbB3. Furthermore, our results show that Olfm4 did not change in ErbB3-IEKO mice, suggesting that increased Atoh1 in ErbB3IEKO is independent to changes in Notch signaling.

NRG $1 \beta$ treatment of enteroids specifically affected PC markers ( Lyz1 and Defa5) and the crypt base columnar ISC marker Lgr5, while effects on the +4 ISC markers Bmi1 and Lrig1 were modest. Since Lrig1 negatively regulates ErbBs, ${ }^{39}$ its gradual reappearance in cultures after treatment might be a compensatory response to ErbB3 activation. However, the regulatory mechanisms surrounding Lrig1 are complex; deletion of Lrig1 in mice resulted in increased EGFR, ErbB2 and ErbB3 expression, but also expansion of PCs and ISCs. ${ }^{40}$ Although ErbB3 levels were higher in these mice, there was no difference in ErbB3 activation. In contrast, there was an increase in P-EGFR and P-ErbB2, which could drive PC and ISC accumulation, consistent with a need for EGF in enteroid cultures to prime and support growth. ErbB3 may be unique among the ErbB family in its ability to downregulate PCs, while other ErbBs either protect (ErbB4) or induce them (EGFR and/ or ErbB2). Lgr5 levels were higher in ErbB3-IEKO ileums, but other cell lineages (and in particular other secretory lineages) did not expand in these mice. Thus, our data support a model of direct effects on PC differentiation rather than a secondary effect of increased ISC proliferation. Unlike other differentiated cell lineages, PCs can persist in expressing $L g r 5,{ }^{41}$ raising the possibility that some of the increase in Lgr5 expression in the ErbB3-IEKO mice is attributable to PCs. The mechanisms through which ErbB3 activation targets Lgr5 $^{+}$ISC either 
directly or indirectly, while out of the scope of this study, merit further investigation.

The sources of ligands for ErbB3 are not fully understood. Multiple ErbB family ligands, including neuregulins 1, 3 and 4, have been detected in intestinal epithelial cells. ${ }^{42}$ On the other hand, a transcriptional profiling study of developing intestine ${ }^{43}$ showed more Nrg1 in the mesenchyme than the epithelium (GEO data set GDS2699); as the intestinal subepithelial myofibroblasts are a rich source of factors supporting epithelial growth and differentiation, it may be that they also provide neuregulins. Alterations in ligand expression occur during inflammation ${ }^{42}$ and colon cancer, ${ }^{44}$ but again little is known about the dynamics and cell specificity of these changes. A comprehensive study of the localization and regulation of neuregulins in the intestine is warranted.

Other growth factor signaling pathways likely interact with ErbB3. Shp2 and MAPK cooperate to shift intestinal secretory cell differentiation away from PCs in favor of goblet cells, ${ }^{14}$ and Fgf10 similarly affects this balance, again presumably through MAPK. ${ }^{45}$ In contrast, an explicit role for PI3K in regulating PCs was not previously tested. NRG1 $\beta$ activates both MAPK and PI3K in intestinal cells, ${ }^{27}$ and crypt progenitor cells from our ErbB3-IEKO mice have reduced activation of both pathways (Figure 7). Inactivation of PI3K or MAPK in HT29 cells induced $L Y Z$ and $A T O H 1$; however, the response to MAPK inhibitor could be overcome by NRG1 $\beta$, while PI3K inhibition was dominant, suggesting mechanistically distinct roles for these pathways. Others have shown that MAPK inhibition leads to differentiation and cell cycle arrest, ${ }^{46,47}$ which might explain an increase in PCs but not the specificity for this lineage. Moreover, we did not find any evidence for altered proliferation in ErbB3-IEKO intestines (Figure 10 and $\mathrm{P}-\mathrm{Rb}$ results in Figure 7c).

In summary, our results demonstrate that ErbB3 restricts $\mathrm{PC}$ numbers via a mechanism involving PI3K-Akt and Atoh1. Understanding the growth factor signaling mechanisms that affect PC function is an intriguing and under-explored area with potential therapeutic benefit. The balance of NRG1/ NRG4 expression is altered in inflammatory bowel disease, ${ }^{27}$ which could alter the equilibrium between ErbB3 and ErbB4 vis-à-vis PC control. Furthermore, the ErbB3 ligand NRG1 is recurrently mutated in patients with colitis-associated colorectal cancers compared with those with sporadic cancer. ${ }^{48}$ This implies functional dysregulation of ErbB3 in the precancerous inflammatory state. Taken together with our study, these reports suggest that continuous alteration of ErbB3 activity might be a risk factor in colitis and possibly inflammation-associated colon cancer.

\section{Materials and Methods}

Animals. All animal use was approved and monitored by the Children's Hospital Los Angeles or Baylor College of Medicine Institutional Animal Care and Use Committees (animal welfare assurance numbers A3276-01 and A3823-01, respectively). C57BI/6 (WT), ErbB4 ${ }^{\text {floxflox }}$ (ErbB4-FF) and ErbB4 floxflox; Villin-Cre (ErbB4-IEKO), ${ }^{49}$ ErbB $3^{\text {floxfflox }}$ (ErbB3-FF) and ErbB3 ${ }^{\text {floxflox; }}$ Villin-Cre (ErbB3IEKO), ${ }^{19}$ Atoh $1^{\text {flox }}{ }^{\text {flox }} ; \mathrm{VilCre}{ }^{\text {ERT2 }}$, Atoh $11^{\text {GFP/GFP }}$ and Atoh $1^{\text {Flag'/Flag } 26,50}$ mice were kept in standard housing with a $12 \mathrm{~h} \mathrm{light/dark}$ cycle at $21^{\circ} \mathrm{C}$ to $22^{\circ} \mathrm{C}$. To achieve deletion of Atoh1 from intestinal epithelium, Atoh $1^{\text {floxfllox;}} ; \mathrm{VilCre}{ }^{\text {ERT2 }}$ mice were given an intraperitoneal injection of $1 \mathrm{mg} /$ mouse tamoxifen (Sigma, St. Louis, MO, USA) dissolved in corn oil for 3 consecutive days, and killed on day 5 . For inflammation studies, acute enteritis was induced by injection of $10 \mathrm{mg} / \mathrm{kg}$ body weight LPS from
Escherichia coli 0111:B4, purified by gel-filtration chromatography (Sigma cat. \#L3012) as we have previously done. ${ }^{51}$ DSS colitis was induced by administering $3 \%$ (w/v) DSS (Affymetrix, Santa Clara, CA, USA) in drinking water for 4 days, followed by 3 days on regular water. ${ }^{27,32}$ Diarrhea was scored on a four-point scale ranging from normal pellets at 0 to liquid stool at 4 . All experiments utilized matched littermate controls, and both male and female animals were included.

Immunofluorescent and histochemical analysis. Hematoxylin and eosin staining was performed on sections of formaldehyde (4\%)-fixed, paraffinembedded ileum (terminal $3 \mathrm{~cm}$ ). Immunofluorescent staining of tissue sections and enteroids used standard techniques as previously reported. ${ }^{27}$ Antigen unmasking was achieved by heating the slides in $10 \mathrm{mM}$ sodium citrate, $\mathrm{pH}$ 6. Nucleotide incorporation for proliferative labeling was performed using a Click-lt EdU labeling kit (Invitrogen, Waltham, MA, USA) according to the manufacturer's protocol.

Antibodies used for immunostaining. Rabbit or goat $\alpha$-Lysozyme (1:150, Dako, Santa Clara, CA, USA, \#A0099, 1:100, Santa Cruz Biotechnology, Dallas, TX, USA, \#Sc-27958 as appropriate for multicolor stains), rabbit $\alpha$-Mucin 2 (1:100, Santa Cruz Biotechnology \#sc-15334), rat $\alpha$-MMP7 (1:50, Vanderbilt University Antibody and Protein Resource), rabbit $\alpha$-ErbB3 (1:100, Cell Signaling, Beverly, MA, USA, \#12708), rabbit $\alpha$-Ki67 (1:400, Cell Signaling \#9129) mouse $\alpha$-ECadherin (1:200, BD Bioscience, San Jose, CA, USA, \#610181), Alexa Fluor 647conjugated donkey $\alpha$-rabbit (1:500, Life Technologies, Waltham, MA, USA, \#A-31573), Alexa Fluor 488-conjugated donkey $\alpha$-goat (1:2000, Life Technologies \#A-11055), Alexa Fluor 546-conjugated goat $\alpha$-rabbit (1:2000, Life Technologies \#A-11035), Cy3-conjugated donkey $\alpha$-mouse (1:200, Jackson ImmunoResearch Laboratories \#715-166-151), FITC-conjugated goat $\alpha$-rat (1:200, Jackson ImmunoResearch Laboratories, West Grove, PA, USA, \#112-095-003), DAPIcontaining mounting medium (Vector Laboratories, Burlingame, CA, USA, \#H-1500) and Hoechst 33342 (ThermoScientific, Waltham, MA, USA, \#62249).

Epithelial isolation. Mucosal scraping was collected as previously described. ${ }^{52,53}$ Briefly, the most distal $6 \mathrm{~cm}$ of the ileum was collected, cut open longitudinally, washed and spread with the mucosal side facing upwards. The mucosa was then scraped by a razor blade positioned at a $45^{\circ}$ angle until the tissue is transparent. Scraping efficiency was confirmed visually under a microscope and by qPCR for Lyz1 expression in scrapings versus submucosa (leftover tissue) compared with the whole tissue.

RNA isolation, RT-PCR and real-time qPCR. RNA was collected from ileal mucosal scrapings, cell cultures or TRIzol-suspended sorted cells using column-based isolation and a TissueLyser LT (Qiagen, Germantown, MD, USA). For RNA-seq, RNA quality controls were performed on an Agilent Bioanalyzer nano chip and RNA integrity number was at least 8.8. For qPCR and RT-PCR, CDNA was synthesized from $1 \mu \mathrm{g}$ of RNA using a High-Capacity cDNA Reverse Transcription Kit (Applied Biosystems, Waltham, MA, USA). qPCR was performed using TaqMAN or SYBR Green (Applied Biosystems) assays, and relative expression determined by the $2^{-\Delta \Delta \mathrm{Ct}}$ method. Reference genes were HPRT, Cdh1 or Gapdh as indicated in each experiment. For RT-PCR, reactions were run for 26 cycles and products were separated on $2 \%$ agarose gels.

Single-cell analysis. lleal mucosal scrapings were collected, washed and processed for DISSECT-CyTOF as previously described. ${ }^{53}$ Protein parameters were quantified on CyTOF1 mass cytometer (Fluidigm, San Francisco, CA, USA) using antibody conjugates previously validated for CyTOF. The cell populations were defined as: epithelial cells $\left(\mathrm{CD}^{-} 5^{-} / \mathrm{CK}_{2} \mathrm{O}^{+}\right)$, crypt progenitors $\left(\mathrm{CK} 2 \mathrm{O}^{\mathrm{low}} / \mathrm{Lyz}^{-}\right)$and PCs $\left(\right.$ Lyz $\left.z^{+}\right)$.

Antibodies for DISSECT-CyTOF analysis. CD45, clone 30-F11; cytokeratin 20, clone D9Z1Z; lysozyme and MMP7, same as for immunofluorescence above; P-Akt (S473), clone D9E; P-ERK1/2 (T202/Y204), clone D13.14.4E; P-RSK (T359/S363), D1E9; P-CREB (S133), clone 87G3; P-Rb (S807/811), clone J112-906; P-S6 (S240/244), clone D68F8; P-ATF-2 (T71), clone 11G2; P-c-Jun (S73), clone D47G9; P-p38 (T180/Y182), clone D3F9; and P-STAT3 (Y705), clone D3A7.

Characterization of Paneth cell granules. Sections from ErbB3-FF and ErbB3-IEKO mice were stained for lysozyme, and granule morphologies were blindly scored in well-oriented crypts using previously published criteria. ${ }^{9,22}$ Briefly, 
normal apically localized lysozyme-positive granules were scored as Norm, Dis (disordered) was basally located granules, Dep (depleted/diminished) was Paneth cells with $<10$ granules, and Diff (diffuse) was Paneth cells with cytoplasmic (not in granules) lysozyme staining. Four mice per phenotype were used with a range from 121 to 243 Paneth cells, which were quantified in at least 40 crypts per mouse.

Protein analysis and western blot. Protein was extracted from ileal mucosal scrapings using previously described protocols. ${ }^{27}$ The samples were quantified by $D_{c}$ protein assay (Pierce, Waltham, MA, USA) and $30 \mu \mathrm{g}$ each separated on SDS-polyacrylamide gels (4-12\%, Invitrogen), transferred onto nitrocellulose membranes and immunoblotted followed by densitometric quantification using the LI-COR Odyssey (LI-COR, Lincoln, NE, USA) infrared detection system.

Antibodies for western blot analysis. From Cell Signaling Technologies, rabbit $\alpha$-total and -phospho-ErbB3 (\#12708, 4791), rabbit $\alpha$-total and -phosphoEGFR (\#4267, 3777), rabbit $\alpha$-phospho-ErbB4 (\#4757), total and phospho-ErbB2, mouse $\alpha$-total Akt (\#2920) and rabbit $\alpha$-phospho-Akt (\#4060), mouse $\alpha$-total Erk1/2 (\#9107) and rabbit $\alpha$-phospho-Erk1/2 (\#4370), rabbit $\alpha$-total and phospho-p38 MAPK (\#9212, 9211), rabbit $\alpha$-CHOP (\#5554), rabbit $\alpha$-cleaved caspase-3 (\#9661), rabbit $\alpha$-JNK2 (\#4672) and mouse $\alpha$-phospho-JNK (\#9255); from Santa Cruz Biotechnology, rabbit $\alpha$-total ErbB4 (\#Sc-283); from LI-COR, donkey $\alpha$-rabbit IRDye 680LT (\#926-68023) and donkey $\alpha$-mouse IRDye 800CW (\#926-32212). Equal loading was monitored by blotting for mouse $\beta$-actin (Sigma-Aldrich, Clone AC-15 \#A1978- 1:10 000).

ATOH $^{+}$cell sorting. Crypts were dissociated as previously described ${ }^{54}$ with TrypLE express (Invitrogen) supplemented with $10 \mu \mathrm{M}$ Y-27632 (Sigma-Aldrich) and $1 \mathrm{mM} \mathrm{N}$-acetylcysteine (Sigma-Aldrich) for $5 \mathrm{~min}$ at $37^{\circ} \mathrm{C}$, strained to remove clumps, pelleted and resuspended in 5\% BSA, $1 \mathrm{mM}$ EDTA and $10 \mu \mathrm{M}$ Y-27632 in $\mathrm{PBS}$. Cell viability was assessed using 7-AAD. ATOH1 ${ }^{+}$and 7-AAD-negative single cells were sorted into $500 \mu \mathrm{l}$ TRIzol reagent (Invitrogen) for RNA sequencing.

Chromatin immunoprecipitation. Purified Atoh $1^{\text {GFP/GFP }}$ or Atoh $1^{\text {Flag/Flag }}$ ileal crypts were crosslinked in RPMI 1640 with $1 \%$ formaldehyde, $50 \mathrm{mM}$ HEPES $\mathrm{pH}$ 8.0, $1 \mathrm{mM}$ EDTA, $1 \mathrm{mM}$ EGTA and $100 \mathrm{mM} \mathrm{NaCl}$ for 30 min, quenched by glycine and washed twice in ice-cold PBS. Chromatin was sonicated to 300-1000 bp fragments in $10 \mathrm{mM}$ Tris-HCl pH 8.0 with $1 \mathrm{mM}$ EDTA pH, $1 \mathrm{mM}$ EGTA and protease inhibitor cocktail (Calbiochem, San Diego, CA, USA, \#539134), and incubated $10 \mathrm{~min}$ in sonication buffer with $0.5 \%$ sarkosyl solution and cleared by centrifugation. Then $500 \mu \mathrm{l}$ sheared chromatin was mixed with $150 \mu \mathrm{l}$ binding buffer ( $440 \mathrm{mM} \mathrm{NaCl}, 0.44 \%$ sodium deoxycholate, $4.4 \%$ Triton X-100) and incubated with Protein G Dynabeads (Invitrogen, \#100-03D) pre-bound to $2 \mu \mathrm{g}$ anti-GFP (Novus, Littleton, CO, USA, NB600-303) at $4{ }^{\circ} \mathrm{C}$ overnight, washed five times in $50 \mathrm{mM}$ HEPES pH 8.0 with $1 \%$ Nonidet P-40, 1\% sodium deoxycholate, $1 \mathrm{mM}$ EDTA and $500 \mathrm{mM} \mathrm{LiCl}$, and eluted at $65^{\circ} \mathrm{C}$ for $15 \mathrm{~min}$ in $50 \mathrm{mM}$ Tris-HCl pH 8.0 with $10 \mathrm{mM}$ EDTA and $1 \%$ SDS. DNA was purified by phenol-chloroform extraction.

In vitro cultures, growth factors, inhibitors and transfections. lleal enteroid cultures were prepared as previously published. ${ }^{6,21}$ Briefly, epithelial crypts were isolated by EDTA $\mathrm{Ca}^{2+}$ chelation and shaking, then embedded in Matrigel (Corning, Corning, NY, USA, 356237) supplemented with EGF (PeproTech, Rocky Hill, NJ, USA, $20 \mathrm{ng} / \mathrm{ml})$, Noggin (R\&D, $100 \mathrm{ng} / \mathrm{ml}$ ), and R-Spondin 1 (R\&D, Minneapolis, MN, USA, $500 \mathrm{ng} / \mathrm{ml}$ ). HT29 human colorectal cancer cells (ATCC, line authenticated by short tandem repeat typing at the USC Bioreagent \& Cell Culture Core Facility and were found to be negative for mycoplasma contamination) were maintained in DMEM with $10 \%$ FBS, 4 mM L-glutamine, and 100 units $/ \mathrm{ml}$ penicillin and streptomycin. Non-transformed, conditionally immortalized MSIE mouse small intestinal enterocyte and YAMC young adult mouse colonocyte lines ${ }^{55}$ were a kind gift from Dr. Robert Whitehead and the Vanderbilt University Digestive Disease Research Center Novel Cell Line Core, where stocks of these lines are characterized, maintained and authenticated. YAMC and MSIE were cultured at $33^{\circ} \mathrm{C}$ in RPMl 1640 with $5 \% \mathrm{FBS}, 5 \mathrm{U} / \mathrm{ml}$ mouse IFN- $\gamma$ (Intergen), $100 \mathrm{U} / \mathrm{ml}$ penstrep and insulin transferrin selenium supplement, and maintained for no more than 3 months in our lab before reverting to a frozen stock vial. All cells were shifted to $0.5 \%$ FBS containing media (no other additives but pen-strep) for $24 \mathrm{~h}$ before experiments. Growth factors and inhibitors were from: NRG1 $\beta$, R\&D; NRG4, Reprokine (Valley Cottage, NY, USA); U0126, Millipore (Temeculah, CA, USA); LY294002, Cell Signaling; BAY 80-6946, ApexBio (Houston, TX, USA); and Rapamycin, MP Biomedicals (Santa Ana, CA, USA). ATOH1-GFP construct on
pcDNA3 background ${ }^{56,57}$ or empty vector were transfected into MSIE and YAMC cells using a Lonza Nucleofector, Kit R (Lonza, Walkersville, MD, USA, VCA-1001).

Gene expression assays and primers. TaqMAN assay numbers used were: Lyz1 (Mm00657323_m1); Lgr5 (Mm00438890_m1); Olfm4 (Mm01320260_m1); Muc2 (Mm01276696_m1); Chga (Mm00514341_m1); Egfr (Mm00433023_m1); ErbB2 (Mm00658541_m1); ErbB4 (Mm01256793_m1); Atoh1 (Mm00476035_s1); Cdh1 (Mm01247357_m1); HPRT (Hs02800695); LYZ (Hs00426232); lfng (Mm01168134_m1); Tnf (Mm00443258_m1). SYBR primer sequences used were:

Defa5 (5'-GCTCAACAATTCTCCAGGTGACCC-3'; 5'-AGCAGACCCTTCTTG GCCTC-3');

Muc2 (5'-ATGCCCACCTCCTCAAAGAC-3'; 5'-GTAGTTTCCGTTGGAACA GTGAA-3');

Lgr5 (5'-ACCTGTGGCTAGATGACAATGC-3'; 5'-TCCAAAGGCGTAGTCTGCTAT-3'); Bmi1 (5'-TGGTTGTTCGATGCATTTCT-3'; 5'-CTTTCATTGTCTTTTCCGCC-3'); Lrig1 (5'-CTCAAAAGCAGCAGAGTCGAT-3'; 5'-GGGAACTCGCTGGACTGC-3');

Gapdh (5'-CACCCAGAAGACTGTGGATGGC-3'; 5'-TGCCTGCTTCACCACCT TCT-3'); Lyz1 (5'-AGCCGATACTGGTGTAATGATGGCA-3'; 5'-CCATGCCACCCA TGCTCGAAT-3').

Statistics. All data represent three or more independent experiments, as indicated in the figure legends. Cohort sizes of ErbB3 $3^{\mathrm{EKO}}$ and WT comparisons were defined based on previous variability observed in lineage markers in order to give $80 \%$ power to detect twofold changes. Samples from one mouse had poor RNA quality and measured parameters were definitive outliers by ROUT test $(Q=0.1 \%)$; this animal was excluded from analysis. Statistical analysis was performed using Prism 5.0 software (GraphPad). Significance of results was tested by ANOVA with Dunnett's post hoc test or Student's t-test as appropriate.

\section{Conflict of Interest}

The authors declare no conflict of interest.

Acknowledgements. We thank the Dixon Cellular Imaging Core at The Saban Research Institute for expert assistance. This work was supported by National Institutes of Health awards R01DK095004 (to MRF), R01DK103831, P30CA068485, P50CA095103, P30DK058404 (to KSL), R01CA142826, R01DK092306 (to NFS), K01DK100485 (to KEH), by a Senior Research Award from the Crohn's and Colitis Foundation of America (to MRF), by a Research Scholar Grant from the American Cancer Society (to MRF), and by a fellowship from the Institute for Research and Medical Consultations at the University of Dammam (DA).

\section{Author contributions}

DA, Y-HL, MAS, KEH, KSL, NFS and MRF conceived and designed the experiments. DA, Y-HL, CVV, AJS, JJH, EBB, MAS, KSL, NFS and MRF performed the experiments and analyzed the data. DA, Y-HL, NFS and MRF wrote the manuscript.

1. Cheng H. Origin, differentiation and renewal of the four main epithelial cell types in the mouse small intestine. IV. Paneth cells. Am J Anat 1974; 141: 521-535.

2. Barker N, van Es JH, Kuipers J, Kujala P, van den Born M, Cozijnsen M et al. Identification of stem cells in small intestine and colon by marker gene Lgr5. Nature 2007; 449: 1003-1007.

3. Peeters T, Vantrappen G. The Paneth cell: a source of intestinal lysozyme. Gut 1975; 16 : $553-558$.

4. Ouellette AJ, Greco RM, James M, Frederick D, Naftilan J, Fallon JT. Developmental regulation of cryptdin, a corticostatin defensin precursor messenger-RNA in mouse small inestinal crypt epithelium. J Cell Biol 1989; 108: 1687-1695.

5. Jones $\mathrm{DE}$, Bevins $\mathrm{CL}$. Paneth cells of the human small intestine express an antimicrobial peptide gene. J Biol Chem 1992; 267: 23216-23225.

6. Sato T, van Es JH, Snippert HJ, Stange DE, Vries RG, van den Born M et al. Paneth cells constitute the niche for Lgr5 stem cells in intestinal crypts. Nature 2011; 469: 415-418.

7. Lewin K. The Paneth cell in disease. Gut 1969; 10: 804-811.

8. Wehkamp J, Salzman NH, Porter E, Nuding S, Weichenthal M, Petras RE et al. Reduced Paneth cell alpha-defensins in ileal Crohn's disease. Proc Natl Acad Sci USA 2005; 102: 18129-18134.

9. Cadwell K, Liu JY, Brown SL, Miyoshi H, Loh J, Lennerz JK et al. A key role for autophagy and the autophagy gene Atg1611 in mouse and human intestinal Paneth cells. Nature 2008; 456: 259-U262.

10. McElroy SJ, Underwood MA, Sherman MP. Paneth cells and necrotizing enterocolitis: a novel hypothesis for disease pathogenesis. Neonatology 2013; 103: 10-20. 
11. Adolph TE, Tomczak MF, Niederreiter L, Ko HJ, Bock J, Martinez-Naves E et al. Paneth cells as a site of origin for intestinal inflammation. Nature 2013; 503: 272-276.

12. Andreu P, Peignon G, Slomianny C, Taketo MM, Colnot S, Robine S et al. A genetic study of the role of the Wnt/beta-catenin signalling in Paneth cell differentiation. Dev Biol 2008; 324: 288-296.

13. VanDussen KL, Carulli AJ, Keeley TM, Patel SR, Puthoff BJ, Magness ST et al. Notch signaling modulates proliferation and differentiation of intestinal crypt base columnar stem cells. Development 2012; 139: 488-497.

14. Heuberger J, Kosel F, Qi JJ, Grossmann KS, Rajewsky K, Birchmeier W. Shp2/MAPK signaling controls goblet/paneth cell fate decisions in the intestine. Proc Natl Acad Sci USA 2014; 111: 3472-3477.

15. Jones JT, Akita RW, Sliwkowski MX. Binding specificities and affinities of egf domains for ErbB receptors. FEBS Lett 1999; 447: 227-231.

16. Prigent SA, Gullick WJ. Identification of c-erbB-3 binding sites for phosphatidylinositol 3'-kinase and SHC using an EGF receptor/c-erbB-3 chimera. EMBO J 1994; 13: 2831-2841.

17. Guy PM, Platko JV, Cantley LC, Cerione RA, Carraway KL 3rd. Insect cell-expressed p180erbB3 possesses an impaired tyrosine kinase activity. Proc Natl Acad Sci U S A 1994; 91: 8132-8136.

18. Shi F, Telesco SE, Liu Y, Radhakrishnan R, Lemmon MA. ErbB3/HER3 intracellular domain is competent to bind ATP and catalyze autophosphorylation. Proc Natl Acad Sci USA 2010; 107: 7692-7697.

19. Lee D, Yu M, Lee E, Kim H, Yang Y, Kim K et al. Tumor-specific apoptosis caused by deletion of the ERBB3 pseudo-kinase in mouse intestinal epithelium. J Clin Invest 2009; 119: 2702-2713.

20. Zhang Y, Dube PE, Washington MK, Yan F, Polk DB. ErbB2 and ErbB3 regulate recovery from dextran sulfate sodium-induced colitis by promoting mouse colon epithelial cell survival. Lab Invest 2012; 92: 437-450.

21. McElroy SJ, Castle SL, Bernard JK, Almohazey D, Hunter CJ, Bell BA et al. The ErbB4 ligand Neuregulin-4 protects against experimental necrotizing enterocolitis. Am J Pathol 2014; 184: 2768-2778.

22. VanDussen KL, Liu TC, Li DL, Towfic F, Modiano N, Winter R et al. Genetic variants synthesize to produce Paneth cell phenotypes that define subtypes of Crohn's disease. Gastroenterology 2014; 146: 200-209.

23. Bry L, Falk P, Huttner K, Ouellette A, Midtvedt T, Gordon JI. Paneth cell-differentaition in the developing intestine of normal and transgenic mice. Proc Natl Acad Sci USA 1994; 91 : 10335-10339.

24. Troughton WD, Trier JS. Paneth and goblet cell renewal in mouse duodenal crypts. J Cell Biol 1969; 41: 251-68.

25. Yang Q, Bermingham NA, Finegold MJ, Zoghbi HY. Requirement of Math1 for secretory cell lineage commitment in the mouse intestine. Science 2001; 294: 2155-2158.

26. Shroyer NF, Helmrath MA, Wang VYC, Antalffy B, Henning SJ, Zoghbi HY. Intestine-specific ablation of mouse atonal homolog 1 (Math1) reveals a role in cellular homeostasis. Gastroenterology 2007; 132: 2478-2488.

27. Bernard JK, McCann SP, Bhardwaj V, Washington MK, Frey MR. Neuregulin-4 is a survival factor for colon epithelial cells both in culture and in vivo. $J$ Biol Chem 2012; 287: 39850-39858

28. Tanaka M, Saito H, Kusumi T, Fukuda S, Shimoyama T, Sasaki Y et al. Spatial distribution and histogenesis of colorectal Paneth cell metaplasia in idiopathic inflammatory bowel disease. J Gastroenterol Hepatol 2001; 16: 1353-1359.

29. Simmonds N, Furman M, Karanika E, Phillips A, Bates AW. Paneth cell metaplasia in newly diagnosed inflammatory bowel disease in children. BMC Gastroenterol 2014; 14: 93

30. Huet C, Sahuquillomerino C, Coudrier E, Louvard D. Absorptive and mucus-secreting subclones isolated from a multipotent intestinal-cell line (HT29) provide new models for cell polarity and terminal differentiation. J Cell Biol 1987; 105: 345-357.

31. Zhao F, Edwards R, Dizon D, Mastroianni JR, Geyfman M, Ouellette AJ et al. Disruption of Paneth and goblet cell homeostasis and increased endoplasmic reticulum stress in Agr2 - / - mice. Dev Biol 2010; 338: 270-279.

32. Frey MR, Edelblum KL, Mullane MT, Liang D, Polk DB. The ErbB4 Growth Factor Receptor Is Required for Colon Epithelial Cell Survival in the Presence of TNF. Gastroenterology 2009; 136: 217-226.

33. Wang GX, Zhao XY, Meng ZX, Kern M, Dietrich A, Chen Z et al. The brown fat-enriched secreted factor Nrg4 preserves metabolic homeostasis through attenuation of hepatic lipogenesis. Nat Med 2014; 20: 1436-1443.

34. Pinkas-Kramarski R, Soussan L, Waterman H, Levkowitz G, Alroy I, Klapper L et al. Diversification of $\mathrm{Neu}$ differentiation factor and epidermal growth factor signaling by combinatorial receptor interactions. EMBO J 1996; 15: 2452-2467.
35. Berger MB, Mendrola JM, Lemmon MA. ErbB3/HER3 does not homodimerize upon neuregulin binding at the cell surface. FEBS Lett 2004; 569: 332-336.

36. Telesco SE, Shih AJ, Jia F, Radhakrishnan R. A multiscale modeling approach to investigate molecular mechanisms of pseudokinase activation and drug resistance in the HER3/ErbB3 receptor tyrosine kinase signaling network. Mol Biosyst 2011; 7: 2066-2080.

37. Steinkamp MP, Low-Nam ST, Yang S, Lidke KA, Lidke DS, Wilson BS. erbB3 is an active tyrosine kinase capable of homo- and heterointeractions. Mol Cell Biol 2014; 34: 965-977.

38. Hellyer NJ, Cheng K, Koland JG. ErbB3 (HER3) interaction with the p85 regulatory subunit of phosphoinositide 3-kinase. Biochem J 1998; 333(Pt 3): 757-763.

39. Laederich MB, Funes-Duran M, Yen L, Ingalla E, Wu X, Carraway KL 3rd et al. The leucinerich repeat protein LRIG1 is a negative regulator of ErbB family receptor tyrosine kinases. J Biol Chem 2004; 279: 47050-47056.

40. Wong VW, Stange DE, Page ME, Buczacki S, Wabik A, Itami S et al. Lrig1 controls intestinal stem-cell homeostasis by negative regulation of ErbB signalling. Nat Cell Biol 2012; 14: 401-408

41. Grun D, Lyubimova A, Kester L, Wiebrands K, Basak O, Sasaki N et al Single-cell messenger RNA sequencing reveals rare intestinal cell types. Nature 2015; 525: 251-255.

42. Feng $Y$, Teitelbaum $D H$. Epidermal growth factor/TNF- $\alpha$ transactivation modulates epithelial cell proliferation and apoptosis in a mouse model of parenteral nutrition. Am J Physiol Gastrointest Liver Physiol 2012; 302: G236-G249.

43. Li X, Madison BB, Zacharias W, Kolterud A, States D, Gumucio DL. Deconvoluting the intestine: molecular evidence for a major role of the mesenchyme in the modulation of signaling cross talk. Physiol Genomics 2007; 29: 290-301.

44. Mitsui K, Yonezawa M, Tatsuguchi A, Shinji S, Gudis K, Tanaka S et al. Localization of phosphorylated ErbB1-4 and heregulin in colorectal cancer. BMC Cancer 2014; 14: 863.

45. Al Alam D, Danopoulos S, Schall K, Sala FG, Almohazey D, Fernandez GE et al. Fibroblast growth factor 10 alters the balance between goblet and Paneth cells in the adult mouse small intestine. Am J Physiol Gastrointest Liver Physiol 2015; 308: G678-G690.

46. Aliaga JC, Deschenes C, Beaulieu JF, Calvo EL, Rivard N. Requirement of the MAP kinase cascade for cell cycle progression and differentiation of human intestinal cells. Am J Physiol Gastrointest Liver Physiol 1999; 277(3 Pt 1): G631-G641.

47. Lemieux E, Boucher MJ, Mongrain S, Boudreau F, Asselin C, Rivard N. Constitutive activation of the MEK/ERK pathway inhibits intestinal epithelial cell differentiation. Am J Physiol Gastrointest Liver Physiol 2011; 301: G719-G730.

48. Robles Al, Traverso G, Zhang M, Roberts NJ, Khan MA, Joseph C et al. Whole-exome sequencing analyses of inflammatory bowel disease-associated colorectal cancers. Gastroenterology 2016; 150: 931-943.

49. Long W, Wagner KU, Lloyd KC, Binart N, Shillingford JM, Hennighausen L et al. Impaired differentiation and lactational failure of Erbb4-deficient mammary glands identify ERBB4 as an obligate mediator of STAT5. Development 2003; 130: 5257-5268.

50. Rose MF, Ren J, Ahmad KA, Chao HT, Klisch TJ, Flora A et al. Math1 is essential for the development of hindbrain neurons critical for perinatal breathing. Neuron 2009; 64 : 341-354.

51. Williams JM, Duckworth CA, Watson AJM, Frey MR, Miguel JC, Burkitt MD et al. A mouse model of pathological small intestinal epithelial cell apoptosis and shedding induced by systemic administration of lipopolysaccharide. Dis Model Mech 2013; 6 : 1388-1399.

52. Perret V, Lev R, Pigman W. Simple method for the preparation of single cell suspensions from normal and tumorous rat colonic mucosa. Gut 1977; 18: 382-385.

53. Simmons AJ, Banerjee A, McKinley ET, Scurrah CR, Herring CA, Gewin LS et al. Cytometrybased single-cell analysis of intact epithelial signaling reveals MAPK activation divergent from TNF-alpha-induced apoptosis in vivo. Mol Syst Biol 2015; 11: 835.

54. Mahe MM, Aihara E, Schumacher MA, Zavros Y, Montrose MH, Helmrath MA et al. Establishment of gastrointestinal epithelial organoids. Curr Protoc Mouse Biol 2013; 3 : 217-240.

55. Whitehead RH, Robinson PS. Establishment of conditionally immortalized epithelial cell lines from the intestinal tissue of adult normal and transgenic mice. Am J Physiol Gastrointest Liver Physiol 2009; 296: G455-G460.

56. Klisch TJ, Xi Y, Flora A, Wang L, Li W, Zoghbi HY. In vivo Atoh1 targetome reveals how a proneural transcription factor regulates cerebellar development. Proc Natl Acad Sci USA 2011; 108: 3288-3293.

57. Lo YH, Chung E, Li Z, Wan YW, Mahe MM, Chen MS et al. Transcriptional regulation by ATOH1 and its target SPDEF in the intestine. Cell Mol Gastroenterol Hepatol 2017; 3. $51-71$. 